\title{
Diagonal Trajectory Posterior Screw Instrumentation for Compromised Bone Quality Spine: Groove-Entry Technique/Hooking Screw Hybrid
}

\author{
Ivan Sekiguchi $^{1)}$, Naoki Takeda ${ }^{2)}$ and Naoki Ishida ${ }^{1)}$ \\ 1) Department of Orthopedic Surgery, Hokuto Medical Corporation Hokuto Hospital, Obihiro, Japan \\ 2) Department of Orthopedic Surgery, Sapporo Orthopedic Cardiovascular Hospital, Sapporo, Japan
}

\begin{abstract}
:
Introduction: In an attempt to increase anchoring strength of posterior instrumentation in spine with compromised bone quality, we introduced diagonal trajectory pedicle screwing (hooking screws) that do not rely on screw thread purchase in bone but rather hook onto the strong posterior elements of vertebrae from inside the bone.

Methods: Between November 2016 and July 2017 we treated eight patients, mean age 80 years old (75-86 years old) with compromised bone quality for spinal instability. The diagnosis was osteoporotic fracture nonunion in three, ankylosed spine fracture in three, pyogenic spondylitis in two cases. All spines were percutaneously instrumented. Groove-entry technique was used for down-going thoracic screws. No additional hooks, cables, or any other augmentation was used. All patients were mobilized on post-operative day 1.

Results: 84 screws were inserted overall. Groove-entry technique was used for 42 screws insertion. On average, 5.3 spinal segments were fixed per case. Mean operation time was $252 \mathrm{~min}$ (46 min per one spinal segment). Mean intraoperative bleeding was $112 \mathrm{ml}$ per case $(21 \mathrm{ml}$ per one fixed spinal segment). All cases achieved bony union of the fracture site or across the destroyed intervertebral disk. Mean time to union was 4 months postop (3-7 months). All patients were ambulatory at the time of discharge. No nerve injury, no skin irritation caused by implants, no screw loosening, no screw pullout, no loss of correction, and no junctional kyphosis were noted in this series.

Conclusions: Diagonal screw instrumentation (our hooking screws and groove-entry technique) appears to provide sufficient anchoring strength while being minimally invasive and possibly helpful in prevention of junctional kyphosis.

Keywords:

Groove-entry technique (GET), diagonal trajectory pedicle screw, hooking screw, osteoporotic spine instrumentation, minimally invasive spinal stabilization (MISt)

Spine Surg Relat Res 2018; 2(4): 309-316 dx.doi.org/10.22603/ssrr.2018-0002
\end{abstract}

\section{Introduction}

This study is a follow-up to original research first reported by Ken Ishii et al. published in Clinical Spine Surgery in $2017^{1)}$.

Aging of the population leads to growing prevalence of osteoporosis and fragility fractures in recent years. Fragility fractures are challenging to treat because compromised bone quality leads to high rates of instrumentation failure ${ }^{2)}$ as well as compression fractures above and below the instrumented vertebrae during follow-up ${ }^{3}$. Junctional kyphosis is a growing problem as well ${ }^{4}$. This led to the use of sublaminar ca- bles $^{5)}$ or hook application ${ }^{6}$ in an attempt to prevent instrumentation failure. However, hooks or cables require a full open approach increasing the invasiveness of the procedure. The damage to ligaments and paravertebral muscle during open approach might increase the incidence of junctional kyphosis.

To increase the anchoring strength, reduce the invasiveness, and prevent junctional kyphosis due to ligaments/muscle separation from bone, we percutaneously insert diagonal trajectory pedicle screws (hooking screws) that hook onto the posterior elements of vertebrae from inside the bone. This is in distinction to the traditional pedicle screws and

Corresponding author: Ivan Sekiguchi, gonchar_ivan@yahoo.co.uk

Received: January 11, 2018, Accepted: February 21, 2018, Advance Publication: April 27, 2018

Copyright (C) 2018 The Japanese Society for Spine Surgery and Related Research 
Table 1. Patients' Background.

\begin{tabular}{ccccc}
\hline $\begin{array}{c}\text { Case } \\
\text { number }\end{array}$ & Sex & $\begin{array}{c}\text { Age } \\
\text { (years) }\end{array}$ & Diagnosis & $\begin{array}{c}\text { Frankel grade } \\
\text { before surgery }\end{array}$ \\
\hline 1 & $\mathrm{~m}$ & 79 & Th6, 7 pyogenic spondylitis & $\mathrm{c}$ \\
2 & $\mathrm{f}$ & 82 & Th9 ankylosed spine fracture & $\mathrm{c}$ \\
3 & $\mathrm{f}$ & 81 & Th11/12 pyogenic spondylitis & $\mathrm{d}$ \\
4 & $\mathrm{f}$ & 84 & Th12 ankylosed spine fracture & $\mathrm{d}$ \\
5 & $\mathrm{f}$ & 84 & Th12 osteoporotic fracture nonunion & $\mathrm{d}$ \\
6 & $\mathrm{f}$ & 76 & L1 osteoporotic fracture nonunion & $\mathrm{d}$ \\
7 & $\mathrm{f}$ & 75 & L1 osteoporotic collapse & $\mathrm{c}$ \\
8 & $\mathrm{f}$ & 86 & Th9 ankylosed spine fracture & $\mathrm{d}$ \\
\hline
\end{tabular}

cortical bone trajectory $(\mathrm{CBT})^{7}$ screws that depend on the screw thread purchase of cortical or cancellous bone $e^{8)}$.

Percutaneous diagonal trajectory pedicle instrumentation was pioneered by Ishii et al. ${ }^{1)}$ who introduced groove-entry technique (GET) for percutaneous down-going diagonal screw insertion in thoracic spine. We expanded on Ishii's concept to insert down-going diagonal screws in the lumbar spine for the first time. We also used up-going diagonal screws in thoracic spine for the first time.

\section{Methods}

\section{Patient demographics}

Between November 2016 and July 2017 we surgically treated spinal instability in eight patients (one male and seven females, mean age 80 years old ranging from 75 to 86 years old, Table 1) with compromised bone quality. The diagnosis was pyogenic spondylitis in two, osteoporotic fracture nonunion in three, ankylosed spine fracture in three cases. All spines were percutaneously instrumented with GET $^{1)}$ and hooking screws. No additional hooks, cables, taping, polymethyl methacrylate (PMMA) injection, or any other augmentation was used. Screw perforation was graded as follows. Grade 1: perforation $<2 \mathrm{~mm}$, grade 2: perforation between 2 and $4 \mathrm{~mm}$, grade 3: screw outside the pedicle $^{9}$. All patients were mobilized on post-operative day 1 (POD1). Perioperative Teriparatide was administered in the three osteoporotic fracture cases only. All patients used hard corsets until bony union was confirmed.

\section{Surgical Procedures}

All patients were operated under general anesthesia in prone position on four-point frame mounted onto a radiolucent operation table. All instrumentation was performed by the same operator. Preoperative planning was performed using sagittal and axial CT sections. 3D CT reconstruction was not necessary for screw insertion planning. All screws and rods were inserted percutaneously under intraoperative $\mathrm{C}$-arm image intensification. Poliaxial percutaneous instrumentation systems were chosen that allow for no $<30^{\circ}$ of screw head angulation to ensure that rods are applied without any stress on the screws. All screws were $60 \mathrm{~mm}$ long.
When small pedicle diameter did not allow screw insertion, extrapedicular insertion ${ }^{10)}$ was used. Soft titanium rods were used in all cases to decrease the mechanical stress on the screws and the junctional spine $e^{4,11}$.

\section{Technique for the mobile spine}

Thoracic screws were inserted according to GET as described by Ishii et al. ${ }^{1)}$ In the lumbar spine, screws were inserted from extraarticular surface of the upper articular process to diagonally transfix the pedicle in a down-going fashion with the intention to hook the screw onto the anterior cortex of the neuroforamen from inside the vertebra (Fig. 1). The screw tip was thus introduced into the inferior corner of the vertebral body. The screw tips were also oriented medially so as to hook the screw shaft onto the cortex of the spinal canal from inside the vertebra.

\section{Technique for the ankylosed spine}

Three vertebra cranial and three caudal to the fracture were instrumented in all cases. Screws above the fracture line were inserted in the up-going fashion, while screws below the fracture were $\mathrm{GET}^{11}$, descending in trajectory so as to provide compression to the fracture site in case of spine telescoping on the screws (Fig. 2).

The endplates were penetrated whenever the screw length allowed. The anterior vertebral body wall or the ossified anterior longitudinal ligament (ALL) was never penetrated to avoid vascular injury and to preserve the anterior column bony integrity.

Screws cranial to the fracture were inserted into thoracic vertebra from the tip of transverse process in an ascending fashion transfixing the transverse process and base of the superior articular process and entering the posterior corner of the next vertebral body, transfixing the next vertebral body in a diagonal fashion (Fig. 3-A and B) and penetrating the cranial endplate of the next vertebra (Fig. 3-C). In this fashion, a single vertebra was instrumented by four screws (Fig. $3-D)$ and every screw engaged strong bony elements of two vertebrae.

\section{Evaluation of outcomes}

Operation time, intraoperative blood loss, complications, incidence of screw loosening, screw pullout, loss of correc- 


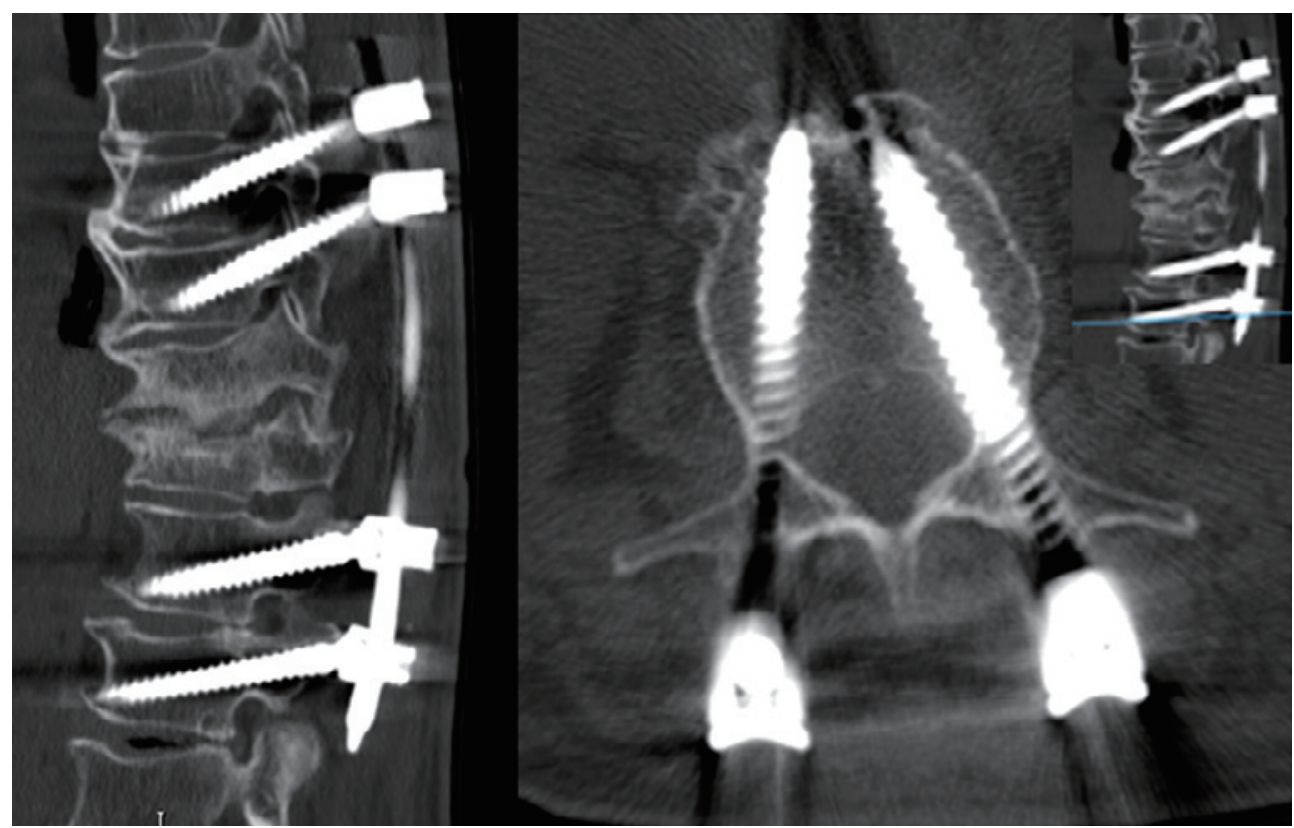

Figure 1. GET/down-going lumbar hooking screws hybrid construct in the mobile spine (case 3) on 6 months postop CT demonstrating the insertion point and down-going trajectory. No signs of screw loosening, pullout, or junctional kyphosis are visible.

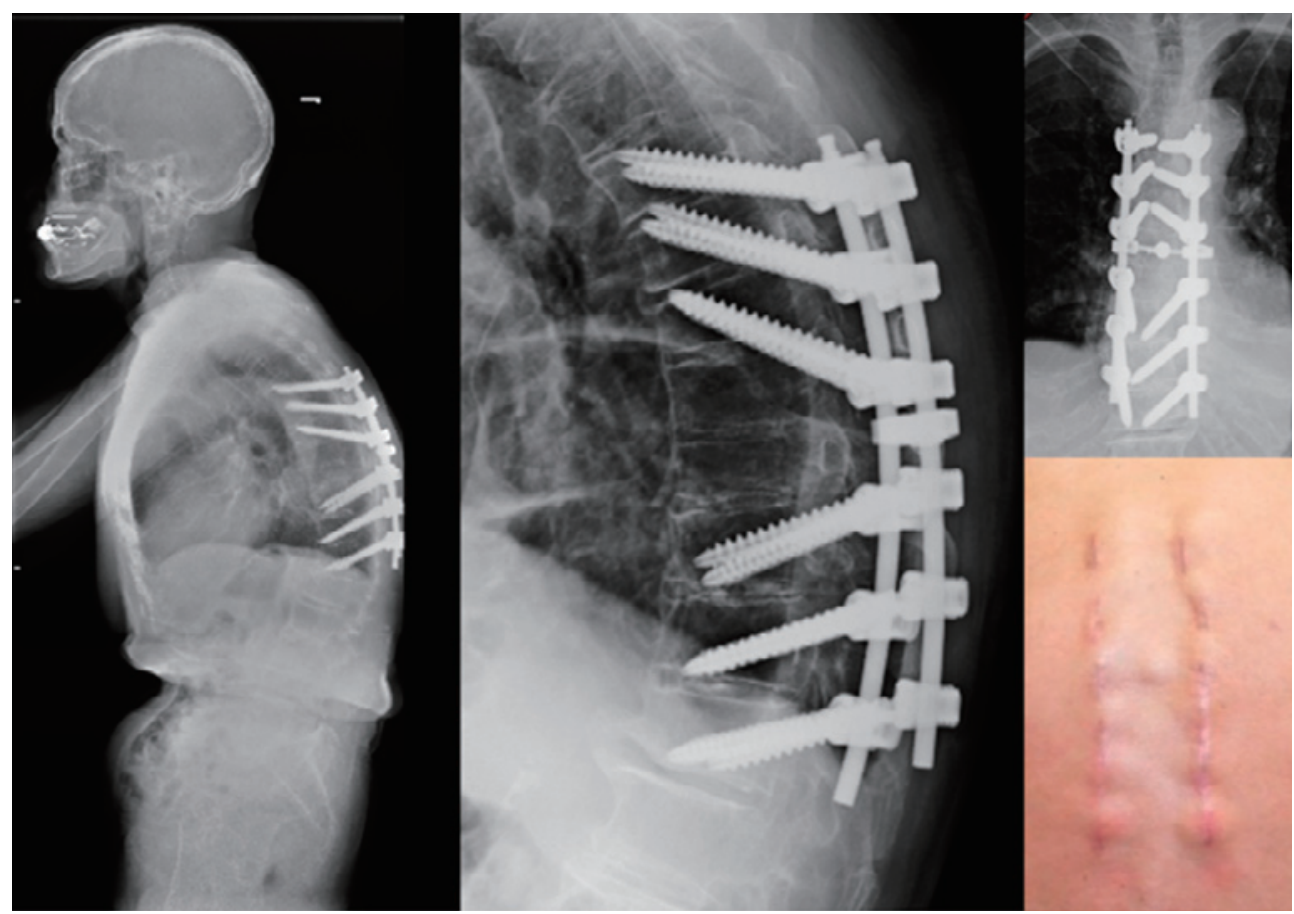

Figure 2. Up-going hooking screws/GET hybrid construct in the ankylosed spine (case 8) on 6 months postop standing X-ray showing the ascending trajectory of the cranial and descending trajectory of the caudal screws. No signs of screw loosening, pullout, or junctional kyphosis are visible. The wounds are healed with minimal scarring. Laminectomy and crosslink application were performed through two screw incisions on the right that became connected. Absence of a midline incision is obvious.

tion, junctional kyphosis, time to bone union, time to hospital discharge, and neurological improvement were evaluated.

Postop CT was compared with CT at 6 months follow-up and the change in distance from screw tips to anterior cortex of vertebral body as well as distance change from the screw heads to the posterior vertebral elements was noticed to evaluate for screw pullout. Loss of correction was evaluated comparing the angle between the cranial endplate of the uppermost instrumented vertebra and caudal endplate of the lowermost instrumented vertebra on postop lateral view $\mathrm{X}$ - 


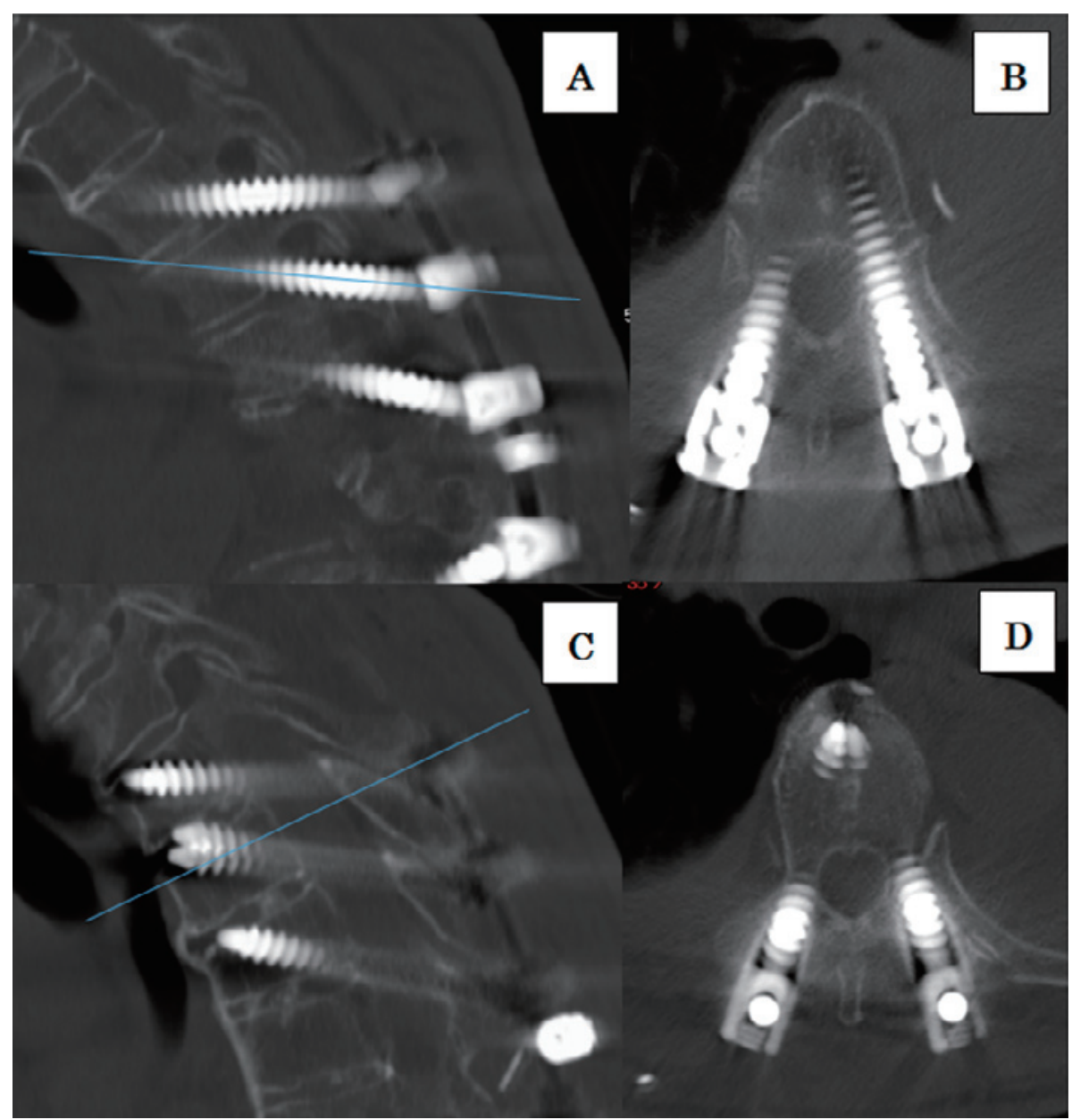

Figure 3.

A and B. Up-going hooking screws inserted in the ankylosed spine (case 8) on 6 months postop CT scans showing the insertion points and ascending trajectories. No signs of screw loosening, pullout or junctional kyphosis are visible.

C. Showing the relationship of screw tips to the disk spaces. Each screw penetrates multiple endplates.

D. A single thoracic vertebra instrumented with four screws.

ray and standing lateral view X-ray at 6 months follow-up. Similarly, changes in alignment of the two junctional vertebrae caudal and cranial to the instrumentation were used to assess for junctional kyphosis.

Monthly postop CTs were scrutinized for radiolucent zones around the screws to evaluate for screw loosening.

Time to bony union was evaluated on monthly CTs, and union was declared when a solid continuous callus was found spanning the fracture site or the destroyed intervertebral disk.

\section{Results}

All patients were unable to walk before the operation due to back pain and some degree of neurologic impairment (Table 1).

The bone quality was deemed compromised in elderly patients with long periods of bed rest ${ }^{12)}$, ankylosed spine, ${ }^{13)}$ or fragility fractures after minor trauma.
Eighty-four screws were inserted overall. Of this number 42 screws were inserted according to groove-entry technique (GET) as described by Ishii et al. ${ }^{1)}$ Mean 5.3 spinal segments were instrumented per case. Four patients also received laminectomy through a small midline incision and case 8 had laminectomy and a crosslink applied thorough two percutaneous screw incisions on the right side that became connected (Table 2).

There were two asymptomatic grade 2 and one asymptomatic grade 3 perforations. There were two postop pneumothorax cases. Both pneumothoraxes were unilateral on the right side and resolved within 5 days postop with a chest tube. There were no nerve injuries or dural tears.

Mean operation time was 252 min (168-350 min, mean 46 min per one spinal segment). Mean intraoperative blood loss was $112 \mathrm{ml}$ per case $(5-300 \mathrm{ml}$, mean $21 \mathrm{ml}$ per spinal segment). All patients were transferred to a rehabilitation facility within 2 weeks postop. All patients improved at least one Frankel grade (Table 3) and were ambulatory at the 
Table 2. Surgical Cases.

\begin{tabular}{|c|c|c|c|c|c|}
\hline $\begin{array}{c}\text { Case } \\
\text { number }\end{array}$ & $\begin{array}{l}\text { Instrumented } \\
\text { vertebrae }\end{array}$ & Other maneuvers & $\begin{array}{l}\text { Operation } \\
\text { time }(\min )\end{array}$ & $\begin{array}{l}\text { Intraoperative } \\
\text { blood loss }(\mathrm{ml})\end{array}$ & $\begin{array}{c}\text { Number of } \\
\text { instrumented } \\
\text { segments }\end{array}$ \\
\hline 1 & Th4-9 & Th6, 7 laminectomy & 330 & 150 & 5 \\
\hline 2 & Th6-12 & Th8 laminectomy & 270 & 250 & 6 \\
\hline 3 & Th9-L2 & Th11, 12 laminectomy & 168 & 150 & 5 \\
\hline 4 & Th8-L3 & L1 biopsy & 220 & 5 & 5 \\
\hline 5 & Th9-L3 & & 205 & 5 & 6 \\
\hline 6 & Th10-L3 & & 200 & 50 & 5 \\
\hline 7 & Th10-L3 & L1, 2 laminectomy & 350 & 300 & 5 \\
\hline 8 & Th6-12 & & 275 & 5 & 6 \\
\hline
\end{tabular}

Table 3. Outcomes.

\begin{tabular}{cccccccc}
\hline $\begin{array}{c}\text { Case } \\
\text { number }\end{array}$ & $\begin{array}{c}\text { Screw } \\
\text { perforation } \\
\text { grade } 2 \text { or } 3\end{array}$ & Complications & $\begin{array}{c}\text { Screw } \\
\text { loosening }\end{array}$ & $\begin{array}{c}\text { Screw } \\
\text { pullout }\end{array}$ & $\begin{array}{c}\text { Loss of } \\
\text { correction }\end{array}$ & $\begin{array}{c}\text { Time to } \\
\text { union } \\
\text { (months) }\end{array}$ & $\begin{array}{c}\text { Frankel } \\
\text { grade at } \\
\text { follow-up }\end{array}$ \\
\hline 1 & None & None & None & None & None & 7 & $\mathrm{~d}$ \\
2 & $\begin{array}{c}1 \text { grade } 2 \\
\text { 1 grade } 3\end{array}$ & None & None & None & None & 4 & $\mathrm{~d}$ \\
3 & None & None & None & None & None & 4 & $\mathrm{e}$ \\
4 & None & Pneumothorax & None & None & None & 3 & $\mathrm{e}$ \\
5 & 1 grade 2 & 1 rib fracture & None & None & None & 3 & $\mathrm{e}$ \\
6 & None & None & None & None & None & 3 & $\mathrm{e}$ \\
7 & None & Pneumothorax & None & None & None & 6 & $\mathrm{e}$ \\
\hline
\end{tabular}

time of discharge from the rehabilitation facility. No skin irritation was caused by implants. None of the patients have surgical site pain, intercostal nerve irritation, or lower extremity pain. All patients were pain medication free by the time of last follow-up. No screw loosening, no screw pullout, no loss of correction, and no junctional kyphosis were noted in this series. All cases achieved bony union as verified by CT scans. Mean time to fracture union was 4 months postop (3-7 months). No reoperations or implant removal was required in any of the eight cases.

Mean follow-up was 10 months (6-13 months). All patients are still under regular follow-up at our outpatient clinic.

\section{Illustrative case (case 2)}

82 year old female living alone was admitted to a hospital by a trauma specialist after a minor fall with back pain, lower extremities numbness, and right wrist swelling. Images showed ankylosed spine from C4 to L3 and a Colles fracture on the right. Th9 fracture was missed because it was nondisplaced. After 1 month of bed rest for back pain, Frankel grade C palsy slowly developed in both lower extremities. At this point, the spine team was consulted for the first time. Images showed Th9 reverse Chance fracture nonunion and spinal cord impingement (Fig. 4-A and B). She was immediately scheduled for surgery and operated on the next day. Screws were inserted from Th6 to Th12 and laminectomy at Th9, 10 was performed. Postoperative course was uneventful, and the patient was transferred to our rehabilitation facility after the wounds healed on POD10. Neurologic function slowly improved until she was able to ambulate with walking aids. Bony union was verified at 4 months postop (Fig. 4-C and D). She was discharged to an assisted elderly facility.

\section{Illustrative case (case 6)}

76-year-old woman with mild dementia was treated conservatively for 4 months for L1 compression fracture without improvement. She was admitted to our facility for definitive therapy. On admission, we noted L1 body collapse with cleft formation and posterior wall defect with mild spinal canal compromise (Fig. 5-A). She was unable to sit up due to back pain and increasing lower extremity pain even with a corset applied. The bone quality was deemed to be very poor due to prolonged bed rest. She was started on daily Teriparatide in preparation for surgery. During the 4 weeks before surgery, her dementia worsened progressively and she became severely depressed. Percutaneous instrumentation was performed from Th10 to L3 skipping L1 (Fig. 5B, C and D). She was mobilized on POD1 with hard corset. Postoperative course was benign. She started standing and walking rehabilitation on POD4 and was transferred to a rehabilitation facility on POD8 with wounds healed. Her mental status improved to pretrauma level within 2 weeks 


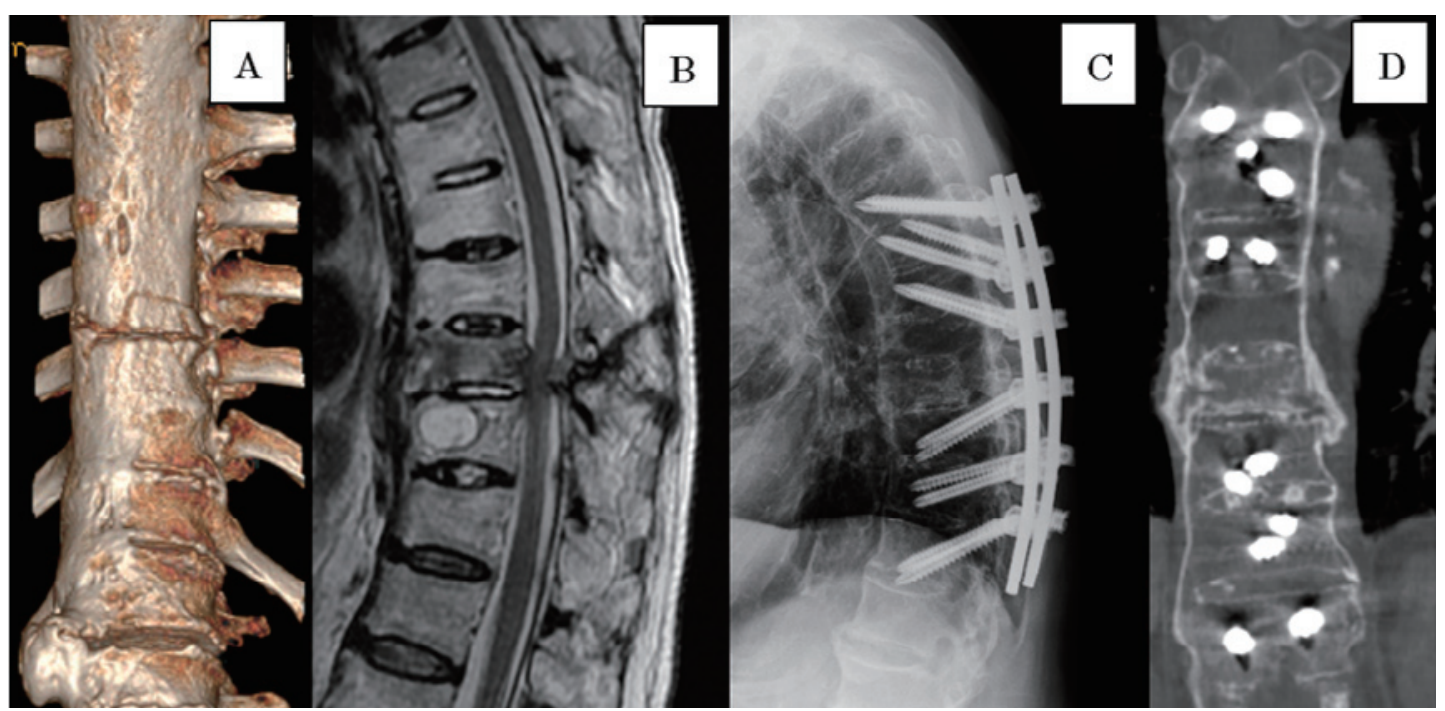

Figure 4. Illustrative case (Case 2).

A. An obvious fracture line of the ankylosed thoracic spine and no evidence of bone healing are visible on preop CT scan 3D reconstruction.

B. Sagittal T2 MRI scan showing fracture line through Th9 body and posterior elements. Bone cyst formation and severe spinal cord compression after 1 month of conservative treatment (bedrest) are visible.

C. No evidence of screw loosening, pullout, or junctional kyphosis is visible on 6 months postop standing lateral X-ray.

D. Bilateral solid bony callus spanning the fracture site is evident on 4 months postop coronal CT scan.

postop. She was able to independently walk by week 6 postop and was discharged home. L1 fracture healing was verified on 3 months postop CT (Fig. 5-B).

\section{Discussion}

Traditional pedicle screw instrumentation of the osteoporotic spine is notoriously difficult because of high incidence of implant failure. Screw loosening, screw pullout, loss of correction, nonunion, and junctional kyphosis are frequently encountered ${ }^{2,4}$. Attempts to overcome these limitations led many surgeons to use bone cement or artificial bone augmentation before screw implantation ${ }^{14}$. To prevent junctional kyphosis, many surgeons opt for hooks ${ }^{6,15)}$ and/or sublaminar cable augmentation ${ }^{5)}$. Unfortunately, none of the techniques is good enough to achieve golden standard status.

Wound healing is impaired in frail, bedridden elderly patients. Longer rods, which are sometimes used for sublaminar taping, may cause skin irritation if junctional kyphosis develops.

GET $^{1)}$ and hooking screw techniques utilize the strength of posterior vertebral elements purchasing transverse and articular process and endplates, transfixing pedicle in a diagonal fashion, and hugging strong cortex of neuroforamen and spinal canal. As a result, we achieved the degree of instrumentation strength with percutaneous diagonal screws only, which appears to be not inferior to traditional full open pedicle screws plus artificial bone augmentation plus sublaminar hooks or taping. Thus, we consider the diagonal screw techniques to be much more cost-effective than tradi- tional open surgery ${ }^{16}$ because no expensive augmentation materials are being used. Also, just like any minimally invasive technique, the diagonal screw techniques allow to reduce blood transfusions, wound care expenses, and postoperative hospital stay length.

In this cohort of eight elderly, frail patients, we did not have any surgical site infection or other wound troubles, which is remarkable for such a big surgical intervention in subjects with compromised healing potential.

The reasons for two pneumothorax cases are unknown. There was no hemothorax accompanying and no lateral screw perforations of the vertebral bodies. Possible reasons for pneumothorax might be unrecognized pleural blebs spontaneously rupturing in the frail elderly patients due to thoracic compression in the prone position on four-point frame or due to positive pressure ventilation during general anesthesia.

The absence of any manifestations of instrumentation failure such as hardware loosening, pullout, loss of correction, or nonunion in our patients signifies the exceptional anchoring potential of the diagonal screws in osteoporotic spine. The positive experience we had with first cases allowed us to decrease the caudal instrumentation from 3 to 2 vertebrae in cases 6 and 7 without compromising the outcomes.

The diagonal trajectory allows for a longer screw insertion. Longer screws have more contact with bone and are more able to engage the anterior column.

Down-going pedicle screw trajectory for thoracic spine was previously described as groove-entry technique (GET) by Ishii et al. ${ }^{1)}$ The difference of lumbar hooking screw from 


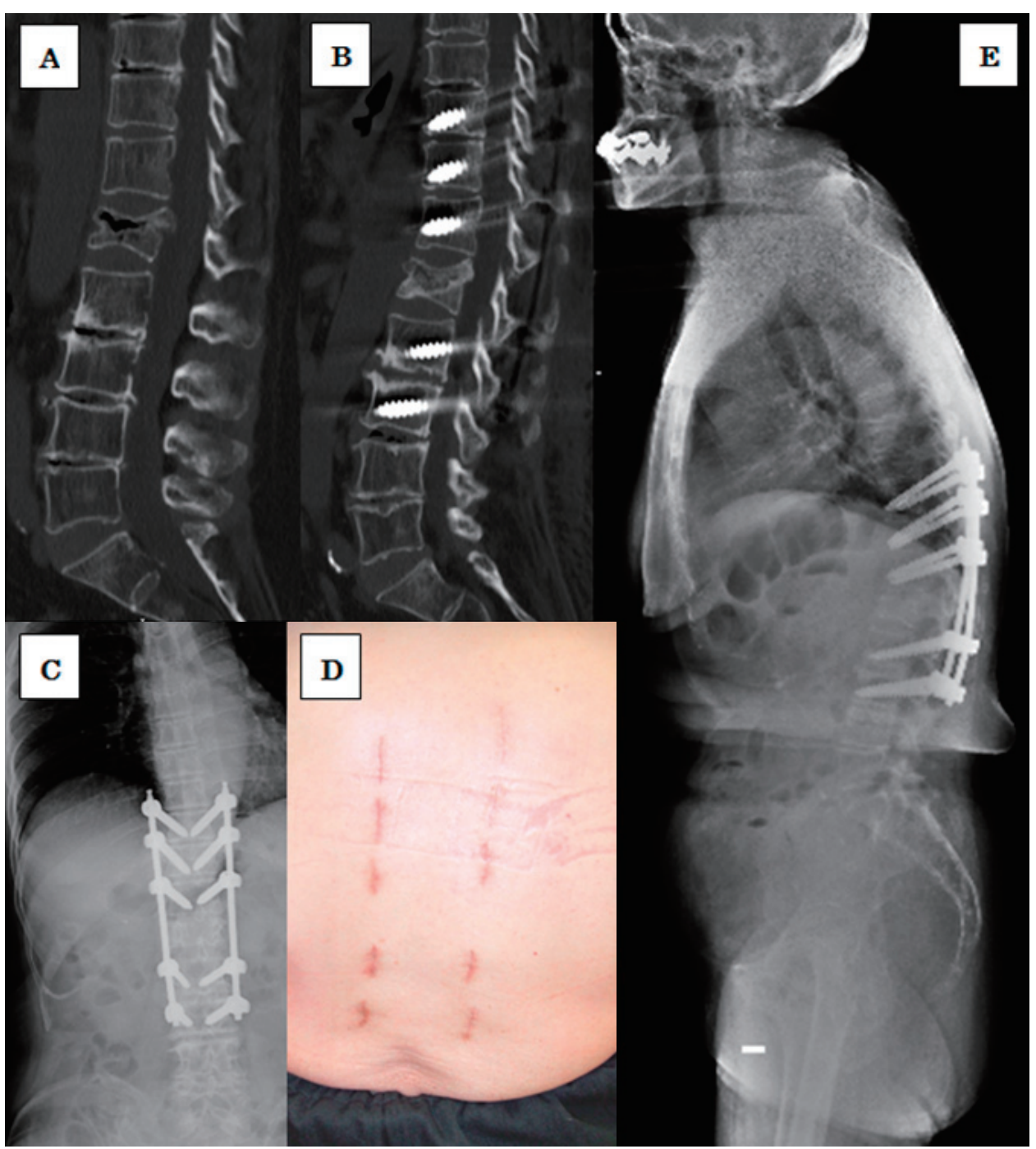

Figure 5. Illustrative case (Case 6).

A. L1 body collapse with cleft formation and posterior wall defect with mild spinal canal compromise.

B. L1 fracture healing, no evidence of screw loosening on 3 months postop CT.

C. 6 months postop standing A-P X-ray.

D. Wounds healed with minimal scarring.

E. 6 months postop standing lateral X-ray shows no signs of screw loosening, pullout, or junctional kyphosis.

GET is that insertion is made from the extraarticular surface of the superior articular process that allows for longer screws and steeper trajectory for caudal endplate penetration in ankylosed spine.

In the upper (cranial) half of ankylosed spine instrumentation, because one screw engages elements of two vertebrae, it is possible to bilaterally instrument up to five vertebra with only six screws if screws of sufficient length are available, which greatly increases strength of fixation/invasion ratio.

Ascending screws penetrating cranial endplate were reported with good outcomes for sacrum instrumentation ${ }^{17)}$, but this is the first report of such technique applied to the thoracic spine to our knowledge.

Because of the diagonal trajectory of the screws, the spine becomes wedged between them preventing any translation of the instrumented vertebrae in the sagittal plane. The fact that the screw tips end up close to the midline allows for a reliable avoidance of large vessel injury under $\mathrm{C}$-arm visualization without the need for CT based navigation, whereas if the screws were inserted straight-in in the sagittal plane, it would be possible to have an anterior perforation even though the screw tip looks to be within the bone on sagittal view of the $\mathrm{C}$-arm because of the rounded shape of anterior vertebral body.

One possible explanation for the absence of junctional kyphosis in our patients might be that percutaneous insertion preserves posterior ligaments and paravertebral muscles necessary for proper alignment and balance postop. Our use of $60-\mathrm{mm}$ long screws to reliably support the anterior column 
might also be important in junctional kyphosis prevention.

\section{Limitations}

More cases and longer follow-up period are desirable in the future reports of this technique.

The oblique trajectory is achievable in weak bone but might be very difficult and dangerous in strong bone of younger patients. This is why we adhere to conventional pedicle screw instrumentation whenever the bone quality is deemed sufficient to expect enough anchoring strength from screw threads.

Percutaneous insertion of the diagonal screws did not give us an opportunity to verify bone surface landmarks for screw starting points. A cadaver study with full open insertion of hooking screws is desirable in the future.

A thorough biomechanical study is desirable to verify our impression concerning the strength of diagonal screw instrumentation and its effects on the junctional spine.

\section{Conclusions}

To our knowledge, this is the second report of the diagonal screw technique application for osteoporotic spine instrumentation, first being GET as described by Ishii et al. ${ }^{1)}$ This technique appears to be minimally invasive, easily reproducible with little learning curve, and provide perfect outcomes in these very challenging cases.

Conflicts of Interest: The authors declare that there are no relevant conflicts of interest.

Acknowledgement: The authors express gratitude to Professor Ken Ishii for reviewing the manuscript and providing academic guidance on groove-entry technique interpretation.

Author Contributions: Ivan Sekiguchi wrote and prepared the manuscript, and all the authors participated in the study design. All authors have read, reviewed, and approved the article.

\section{References}

1. Ishii K, Shiono Y, Funao H, et al. A novel groove-entry technique for inserting thoracic percutaneous pedicle screws. Clin Spine Surg. 2017 Mar;30(2):57-64.

2. Paxinos O, Tsitsopoulos PP, Zindrick MR, et al. Evaluation of pullout strength and failure mechanism of posterior instrumentation in normal and osteopenic thoracic vertebrae. J Neurosurg Spine. 2010 Oct;13(4):469-76.

3. Yang P, Zhang Y, Ding HW, et al. Pedicle screw fixation with kyphoplasty decreases the fracture risk of the treated and adjacent non-treated vertebral bodies: a finite element analysis. J Huazhong Univ Sci Technolog Med Sci. 2016 Dec;36(6):887-94.

4. Han S, Hyun SJ, Kim KJ, et al. Rod stiffness as a risk factor of proximal junctional kyphosis after adult spinal deformity surgery: comparative study between cobalt chrome multiple-rod constructs and titanium alloy two-rod constructs. Spine J. 2017 Jul;17(7): 962-8.

5. Sun E, Alkalay R, Vader D, et al. Preventing distal pullout of posterior spine instrumentation in thoracic hyperkyphosis: a biomechanical analysis. J Spinal Disord Tech. 2009 Jun;22(4):270-7.

6. Karakaşlı A, Sekik E, Karaarslan A, et al. Are pedicular screws and lateral hook screws more resistant against pullout than conventional spinal hooks and screws in terminal vertebral segment fixation? Eklem Hastalik Cerrahisi. 2016;27(1):22-8.

7. Santoni BG, Hynes RA, McGilvray KC, et al. Cortical bone trajectory for lumbar pedicle screws. Spine J. 2009 May;9(5):366-73.

8. Inceoglu S, Ferrara L, McLain RF. Pedicle screw fixation strength: pullout versus insertional torque. Spine J. 2004 Sep-Oct;4(5):5138.

9. De Paula Guedes V, Maniffra EF, Aguiar LR. Image-guided surgery in the spine: neuronavigation vs. fluoroscopy. Columna. 2015;14(3):181-5.

10. Fu CF, Liu Y, Zhang SK, et al. Biomechanical study on pullout strength of thoracic extrapedicular screw fixation. Chin J Traumatol. 2006 Dec;9(6):374-6.

11. Han S, Hyun SJ, Kim KJ, et al. Comparative Study Between Cobalt Chrome and Titanium Alloy Rods for Multilevel Spinal Fusion: Proximal Junctional Kyphosis More Frequently Occurred in Patients Having Cobalt Chrome Rods. World Neurosurg. 2017 Jul; 103: 404-9.

12. Endo I, Matsumoto T. [Space flight/bedrest immobilization and bone. Bisphosphonate and the loss of bone mineral due to space flight or prolonged bed rest]. Clin Calcium. 2012 Dec;22(12): 1863-70.

13. Leone A, Marino M, Dell'Atti C, et al. Spinal fractures in patients with ankylosing spondylitis. Rheumatol Int. 2016 Oct;36(10): 1335-46.

14. Burval DJ, McLain RF, Milks R, et al. Primary pedicle screw augmentation in osteoporotic lumbar vertebrae: biomechanical analysis of pedicle fixation strength. Spine (Phila Pa 1976). 2007 May 1;32(10):1077-83.

15. Hackenberg L, Link T, Liljenqvist U. Axial and tangential fixation strength of pedicle screws versus hooks in the thoracic spine in relation to bone mineral density. Spine (Phila Pa 1976). 2002 May 1;27(9):937-42.

16. Joestl J, Lang N, Bukaty A, et al. Osteoporosis associated vertebral fractures-Health economic implications. PLoS One. 2017 May 22;12(5):e0178209.

17. Matsukawa K, Yato Y, Kato T, et al. Cortical bone trajectory for lumbosacral fixation: penetrating S-1 endplate screw technique: technical note. J Neurosurg Spine. 2014 Aug;21(2):203-9.

Spine Surgery and Related Research is an Open Access journal distributed under the Creative Commons Attribution-NonCommercial-NoDerivatives 4.0 International License. To view the details of this license, please visit (https://creativeco mmons.org/licenses/by-nc-nd/4.0/). 